2016-03

\title{
Investigating attentional processes in depressive-like domestic horses (Equus caballus).
}

\section{Rochais, C}

http://hdl.handle.net/10026.1/10413

\subsection{6/j.beproc.2015.12.010}

Behav Processes

All content in PEARL is protected by copyright law. Author manuscripts are made available in accordance with publisher policies. Please cite only the published version using the details provided on the item record or document. In the absence of an open licence (e.g. Creative Commons), permissions for further reuse of content should be sought from the publisher or author. 


\section{Investigating attentional processes in depressive-like domestic horses (Equus caballus).}

${ }^{1}$ Université de Rennes 1, UMR CNRS 6552 -Laboratoire Ethologie Animale et HumaineEthoS- Station biologique, 35380, Paimpont, France

${ }^{2}$ CNRS- UMR 6552 Université de Rennes 1, -Laboratoire Ethologie Animale et Humaine263 avenue du général Leclerc, 35042, Rennes cedex, France

${ }^{3}$ School of Veterinary Sciences, Department of Animal and Poultry Science, University of Guelph, 50 Stone Road East Guelph, N1G2W1, Canada. Present address: Centre for Behavioural Biology, Department of Clinical Veterinary Science, University of Bristol, Langford House, Langford BS40 5DU, UK

*Corresponding author: celine.rochais@gmail.com

Tel : +33 (0)2.99.61.81.55.

UMR CNRS 6552 "Ethologie Animale et Humaine"

Université de Rennes 1

Station Biologique de Paimpont

35380 Paimpont 


\section{Abstract}

Some captive/domestic animals respond to confinement by becoming inactive and unresponsive to external stimuli. Human inactivity is one of the behavioural markers of clinical depression, a mental disorder diagnosed by the co-occurrence of symptoms including deficit in selective attention. Some riding horses display 'withdrawn' states of inactivity and low responsiveness to stimuli that resemble the reduced engagement with their environment of some depressed patients. We hypothesized that 'withdrawn' horses experience a depressive-like state and evaluated their level of attention by confronting them with auditory stimuli. Five novel auditory stimuli were broadcasted to 27 horses, including 12 'withdrawn' horses, for 5 days. The horses' reactions and durations of attention were recorded. Nonwithdrawn horses reacted more and their attention lasted longer than that of withdrawn horses on the first day, but their durations of attention decreased over days, but those of withdrawn horses remained stable. These results suggest that the withdrawn horses' selective attention is altered, adding to already evidenced common features between this horses' state and human depression.

Key words: horses; attention; cognition; welfare; depression; 4

(1)

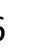

7

\section{0} 61 62 


\section{Introduction}

One of captive/domestic animals' responses to confinement is to become inactive and unresponsive to external stimuli (Fuchs \& Flügge, 2002), as reported for many lab/farm species experiencing inappropriate living conditions (e.g. fur-farmed mink; tethered sows; caged dogs, Cronin, 1985). Humans' inactivity is one of the behavioural markers of clinical depression (APA, 2013), a complex heterogeneous mental disorder diagnosed by the cooccurrence of affective, cognitive and behavioural symptoms (APA, 2013). Symptoms include deficits in selective attention (i.e. ability to focus perception on one stimulus while filtering out other simultaneous stimuli, Posner et al., 1980), as evidenced e.g. by slower reactions in an auditory oddball task (Kemp et al., 2010). Most reports of horses' impaired welfare (Burn et al., 2010; Pritchard et al., 2005) or pain (e.g. Ashley et al., 2005; review in Hausberger et al., in press) indicate that some horses are unresponsive to environmental stimuli. A 'withdrawn' state was recently described more formally (Fureix et al., 2012): during a withdrawn bout, horses remain totally motionless (immobility with no neck, head, and ear movements); displaying a flat-necked posture; wide open, rarely blinking eyes; and backwards-pointing ears. Compared to non-withdrawn horses from the same stable, withdrawn horses react less to human approach and tactile stimulation, and consume less sucrose (Fureix et al., 2015), a sign of anhedonia i.e. loss of interest or pleasure (Willner et al., 1992), which is a core symptom of human clinical depression. We hypothesized that if withdrawn horses were in a depression-like condition their selective attention would be altered (Greimel et al., 2015). Therefore we submitted 12 withdrawn horses and 15 nonwithdrawn control horses from the same stable to unfamiliar auditory stimuli.

\section{Material and Methods}

\subsection{Ethical note}

This study complied with French laws related to animal experimentation and the European directive 86/609/CEE.

\subsection{Subjects}

Twenty-seven horses $\left(\mathrm{N}_{\text {mares }}=6\right.$; $\mathrm{N}_{\text {geldings }}=21$; aged 5 -20 years, $\bar{X} \pm \mathrm{SE}=12.7 \pm 0.9,77 \%$ French Saddlebred) from the same riding school were observed in June 2012. The horses were kept in $3 \mathrm{~m} * 3 \mathrm{~m}$ individual straw-bedded stalls in a barn, allowing visual contact with conspecifics. 
Each stall was cleaned every morning, and was equipped with an automatic drinker. Animals were fed hay once a day (13:00 h), and commercial pellets three times a day (07:00 h, 12:00 h, 19:00 h). Groups of 7-8 horses were released (allowing contact) into barren paddocks for two days at the week-end. Horses worked in riding lessons for 6-10 hours a week (two rest days). The time each horse spent being withdrawn in its stall was determined using instantaneous scan sampling (Altmann, 1974) every 2 minutes for $1 \mathrm{~h}$ periods, repeated daily at different times of day (from 6:00 a.m. to 9:00 p.m.) over 15 days (average number of total scans per subject: $907 \pm 11.14$ ) (Fureix et al., 2015). Twelve of the 27 horses $\left(\mathrm{N}_{\text {mares }}=3\right.$; $\mathrm{N}_{\text {geldings }}=9$; called withdrawn horses hereafter) displayed the previously described withdrawn state at least once.

\subsection{Test settings}

Five stimuli, all initially novel for the subjects, were broadcasted within the stable: three vocalizations of different species (baboon, barnacle goose and whale), one vocalization of an unfamiliar conspecific, and one non-biological sound (piano music). Horses were randomly exposed by groups of 4-6 in neighbouring stalls, following Noble et al., (2013), to one of the five auditory stimuli, which differed for each group on a given day (e.g. the $1^{\text {st }}$ test day, the $1^{\text {st }}$ group heard the baboon, the $2^{\text {nd }}$ the whale etc; the $2^{\text {nd }}$ test day the $1^{\text {st }}$ group heard the piano, the $2^{\text {nd }}$ the baboon etc). The loudspeaker (Nagra Kudelski HP monitor ${ }^{\circledR}$ ) was at equal distances $(2 \mathrm{~m})$ from each horse. Stimuli were broadcast for 3 seconds at $80 \mathrm{db}$, always between 13:00h and 14:00h and for 5 consecutive days. Data collected on the fifth test day were discarded, due to a different (from the other test days) horses' management (i.e. no riding activities). Proportions of non-withdrawn and withdrawn horses were balanced within each group. Observations focused on small groups because we could not isolate subjects, or observe all the 27 horses simultaneously in the barn.

\subsection{Behavioural measurements}

Tests were videotaped (Sony HDR-XR105®) and standard measures of attentional states were extracted from videos using continuous focal sampling (Altmann, 1974). We recorded the presence or absence of reaction (i.e. change in behaviour interrupting the ongoing activity after a broadcast, characterized by any ear, head, neck or whole body movement) to estimate attentional capture. We recorded the total duration of attention (i.e. standing motionless with 
eyes, ears, head or neck oriented towards the loudspeaker (Waring, 2003)) during the 5 minutes following a broadcast. Three horses (1 non-withdrawn, 2 withdrawn) were scared by the stimuli on the $1^{\text {st }}$ and $2^{\text {nd }}$ test days (i.e. alarm posture associated with dilated nostrils and snorting and active walking in the box; Kiley-Worthington, 1976, Wolff et al., 1997). As these horses did not show any attention patterns, they were excluded from the analyses, so our analyses included only 24 horses.

\subsection{Statistical analyses}

Normality and homogeneity of variances were assessed by inspection of residuals and Shapiro-Wilk W tests (Ha and Ha, 2011). Because our data were not normally distributed, we applied non-parametric statistical tests (Siegel and Castellan, 1988). Fisher's exact and Chisquare tests were used to evaluate the influence of test day on the proportion of reactive versus non-reactive horses. Friedman tests, followed by multiple pairwise comparisons using Wilcoxon signed rank t-tests applying a False discovery rate correction (Benjamini and Hochberg, 2000) were used to evaluate relationships between duration of attention, stimulus type and test day. Kruskall-Wallis tests were used to assess relationships between duration of attention and group observation. Mann-Whitney U-tests (for each test day) compared durations of attention between non-withdrawn (NW) and withdrawn (W) horses, and gelding/mares. Analyses were conducted using R software (accepted two-tailed p level at 0.05). Descriptive statistics are means ( $\bar{X}$ ) followed by standard errors (SE).

\section{Results}

Neither sex nor type of stimulus nor observation group influenced reactions and durations of attention significantly (sex: Mann-Whitney U-tests, $\mathrm{P}>0.05$; stimuli: Friedman tests, 1.2 $<\mathrm{F}<7.2$, P $>0.05$; group: Kruskall-Wallis tests, $6.8<\mathrm{H}<10.2, \mathrm{P}>0.05$ ), therefore data were pooled for subsequent analyses.

\subsection{First test day}


More NW horses (93\%) than W horses (50\%) reacted (Fisher exact Test, $\mathrm{P}=0.02$ ) (Fig. 1). Reaction times ranged from 0.41 to 4.48 seconds ( $\bar{X}=1.8 \pm 0.2$ seconds), but did not differ between NW and W horses (Mann-Whitney U-test: $\mathrm{N}_{\mathrm{NW}}=14, \mathrm{~N}_{\mathrm{W}}=10, \bar{X}_{\mathrm{NW}}=2.0 \pm 0.2 \mathrm{~s}$, $\left.\bar{X}_{\mathrm{w}}=1.2 \pm 0.2 \mathrm{~s} ; \mathrm{U}=28, \mathrm{P}=0.27\right)$.

Durations of attention in reactive horses varied between subjects (from 1.0 to 10.8 seconds, $\bar{X}=4.2 \pm 0.7$ ) and were longer for NW horses than for W horses (Mann-Whitney Utest: $\mathrm{N}_{\mathrm{NW}}=14, \mathrm{~N}_{\mathrm{w}}=10, \bar{X}_{\mathrm{NW}}=5.6 \pm 0.8 \mathrm{~s}, \bar{X}_{\mathrm{w}}=2.4 \pm 1.1 \mathrm{~s} ; \mathrm{U}=38, \mathrm{P}=0.01$ ) (Fig. 2).

\subsection{Changes of response to auditory stimuli in relation to time}

Although all horses paid attention to the auditory stimuli at least once, patterns of response of $\mathrm{W}$ and $\mathrm{NW}$ horses differed in relation to time. The proportion of reactive $\mathrm{W}$ horses increased significantly on day $2\left(\mathrm{X}^{2}=10.5 \mathrm{p}=0.0002\right)$ and remained high on the following days, contrary to NW horses (Fig. 1). Durations of attention of NW horses decreased on day 2 compared to day 1 (Friedman test $(\mathrm{N}=14, \mathrm{df}=4)=12.4 \mathrm{p}=0.01$; Wilcoxon signed-rank test $\bar{X}_{\mathrm{D} 1}=5.6 \pm 10.8 \mathrm{~s}, \bar{X}_{\mathrm{D} 2}=2.9 \pm 0.6 \mathrm{~s}, \bar{X}_{\mathrm{D} 3}=3.1 \pm 10.7, \bar{X}_{\mathrm{D} 4}=3.7 \pm 0.5, \mathrm{p}<0.05$ for all), whereas they did not vary significantly for $\mathrm{W}$ horses (Friedman test $(\mathrm{N}=10, \mathrm{df}=4)=1.3$ $\mathrm{p}=0.85$ ) (Fig. 2).

\section{Discussion}

Playback of unfamiliar auditory stimuli elicited reactions of non-withdrawn horses but of only half of the withdrawn horses on the first day. Durations of attention of reactive nonwithdrawn horses were longer than those of reactive withdrawn horses. Non-withdrawn horses' durations of attention decreased on the following days, but those of withdrawn horses did not vary significantly.

On the first test day, withdrawn horses seemed to have "switched off" auditory stimuli compared to non-withdrawn horses. This result is in accordance with Fureix et al.'s (2012) study reporting withdrawn horses' lower levels of reactions towards humans and tactile stimuli. This "switch off" might reflect the withdrawn horses' lack of selective attention towards unusual stimuli. Several hypotheses have been proposed to explain the depressed 
human patients' lowered selective attention: 1) negative emotional states draw attention and thus interrupt associated behaviour: the more intensive a negative emotional state, the more it can disrupt attention to anything else (Smith et al., 1985; Williams, 2002); and 2) the resource allocation hypothesis postulates that because the depressed patients' cognitive capacity is reduced, they have deficits in engaging in effortful cognitive processes such as focusing on relevant stimulations (Ellis \& Ashbrook, 1988, cited by Gotlib \& Joormann, 2010). In this study, both hypotheses may apply. The complete immobility, the backward ears and lack of eye blinking (Fureix et al., 2012) argue in favour of inward oriented attention more than attention oriented towards the environment. This hypothesis is confirmed by our data on attention for novel auditory stimuli. Thus, horses with impaired welfare may not perform cognitive tasks well (Hausberger et al., 2007).

With time, the subjects' reactions to our tests varied. More withdrawn horses reacted on the second day and this proportion remained similar subsequently, while a reverse pattern was observed for the non-withdrawn horses. Withdrawn horses could have difficulties to detect or differentiate novel or relevant stimuli in their environment, and this could be related to cognitive control deficits affecting individuals' ability to disengage attention from irrelevant material, a common feature of human depressed patients (Gotlib and Joormann, 2010; Kemp et al., 2010).

This study reveals that a horses' 'withdrawn state' corresponds to a multifaceted syndrome including lower reactivity to environmental stimuli suggesting selective attentional impairments, a common trait of human depressed patients (Gotlib and Joormann, 2010). Replication and further research on withdrawn horses' attentional processes are needed, before validating it for a spontaneous model of depression.

\section{Acknowledgments}

We would like to thank the managers of the riding school for allowing us to work with their horses and all staff for their help and cooperation. This work was supported by a doctoral grant from the French Research Minister (CR), a Fyssen foundation postdoctoral fellowship (CF), a grant from the French Canada Research Fund, and from the Institut Français du Cheval et de l'Equitation (IFCE). The project benefitted from discussions from the GIS CCS. The funders had no role in the study design, data collection and analysis, decision to publish 
or preparation of the manuscript. The authors report no conflicts of interest. We thank the anonymous referees for their comments on the manuscript.

\section{References}

Altmann, J., 1974. Observational Study of Behavior: Sampling Methods. Behaviour 49, 227266. doi:10.1163/156853974X00534

APA, A.P., 2013. The Diagnostic and Statistical Manual of Mental Disorders, Fifth Edition.: DSM 5. bookpointUS.

Ashley, F.H., Waterman-Pearson, A.E., Whay, H.R., 2005. Behavioural assessment of pain in horses and donkeys: application to clinical practice and future studies. Equine Vet. J. 37, 565-575. doi:10.2746/042516405775314826

Benjamini, Y., Hochberg, Y., 2000. On the Adaptive Control of the False Discovery Rate in Multiple Testing With Independent Statistics. J. Educ. Behav. Stat. 25, 60-83. doi:10.3102/10769986025001060

Burn, C.C., Dennison, T.L., Whay, H.R., 2010. Relationships between behaviour and health in working horses, donkeys, and mules in developing countries. Appl. Anim. Behav. Sci. 126, 109-118. doi:10.1016/j.applanim.2010.06.007

Fuchs, E., Flügge, G., 2002. Social stress in tree shrews: Effects on physiology, brain function, and behavior of subordinate individuals. Pharmacol. Biochem. Behav. 73, 247-258. doi:10.1016/S0091-3057(02)00795-5

Fureix, C., Beaulieu, C., Argaud, S., Rochais, C., Quinton, M., Henry, S., Hausberger, M., Mason, G., 2015. Investigating anhedonia in a non-conventional species: Do some riding horses Equus caballus display symptoms of depression? Appl. Anim. Behav. Sci. 162, 26-36. doi:10.1016/j.applanim.2014.11.007

Gotlib, I.H., Joormann, J., 2010. Cognition and Depression: Current Status and Future Directions. Annu. Rev. Clin. Psychol. 6, 285-312. doi:10.1146/annurev.clinpsy.121208.131305

Greimel, E., Trinkl, M., Bartling, J., Bakos, S., Grossheinrich, N., Schulte-Körne, G., 2015. Auditory selective attention in adolescents with major depression: An event-related potential study. J. Affect. Disord. 172, 445-452. doi:10.1016/j.jad.2014.10.022

Ha, R.R., Ha, J.C., 2011. Integrative Statistics for the Social and Behavioral Sciences. SAGE. Hausberger, M., Gautier, E., Müller, C., Jego, P., 2007. Lower learning abilities in stereotypic horses. Appl. Anim. Behav. Sci. 107, 299-306. doi:10.1016/j.applanim.2006.10.003

Hausberger, M., Fureix, C., Lesimple, C., in press. Detecting horses’ sickness: in search of visible signs.

Kemp, A.H., Pe Benito, L., Quintana, D.S., Clark, C.R., McFarlane, A., Mayur, P., Harris, A., Boyce, P., Williams, L.M., 2010. Impact of depression heterogeneity on attention: An auditory oddball event related potential study. J. Affect. Disord. 123, 202-207. doi:10.1016/j.jad.2009.08.010

Kiley-Worthington, M., 1976. The tail movements of ungulates, canids and felids with particular reference to their causation and function as displays. Behaviour 56, 69-115. doi:10.1163/156853976X00307

Noble, G.K., Blackshaw, K.L., Cowling, A., Harris, P.A., Sillence, M.N., 2013. An objective measure of reactive behaviour in horses. Appl. Anim. Behav. Sci. 144, 121-129. doi:10.1016/j.applanim.2012.12.009 
Posner, M.I., Snyder, C.R., Davidson, B.J., 1980. Attention and the detection of signals. J. Exp. Psychol. Gen. 109, 160-174. doi:10.1037/0096-3445.109.2.160

Pritchard, J.C., Lindberg, A.C., Main, D.C.J., Whay, H.R., 2005. Assessment of the welfare of working horses, mules and donkeys, using health and behaviour parameters. Prev. Vet. Med. 69, 265-283. doi:10.1016/j.prevetmed.2005.02.002

Siegel, S., Castellan, N.J., 1988. Nonparametric statistics for the behavioral sciences. McGraw-Hill, New York.

Smith, D.T.W., Ingram, R.E., Roth, D.L., 1985. Self-focused attention and depression: Selfevaluation, affect, and life stress. Motiv. Emot. 9, 381-389. doi:10.1007/BF00992207

Waring, G.H., 2003. Horse Behavior. Noyes Publications/William Andrew Pub.

Williams, A.C. de C., 2002. Facial expression of pain, empathy, evolution, and social learning. Behav. Brain Sci. 475.

Willner, P., Muscat, R., Papp, M., 1992. Chronic mild stress-induced anhedonia: A realistic animal model of depression. Neurosci. Biobehav. Rev. 16, 525-534. doi:10.1016/S0149-7634(05)80194-0

Wolff, A., Hausberger, M., Le Scolan, N., 1997. Experimental tests to assess emotionality in horses. Behav. Processes 40, 209-221. doi:10.1016/S0376-6357(97)00784-5 
284

285

286

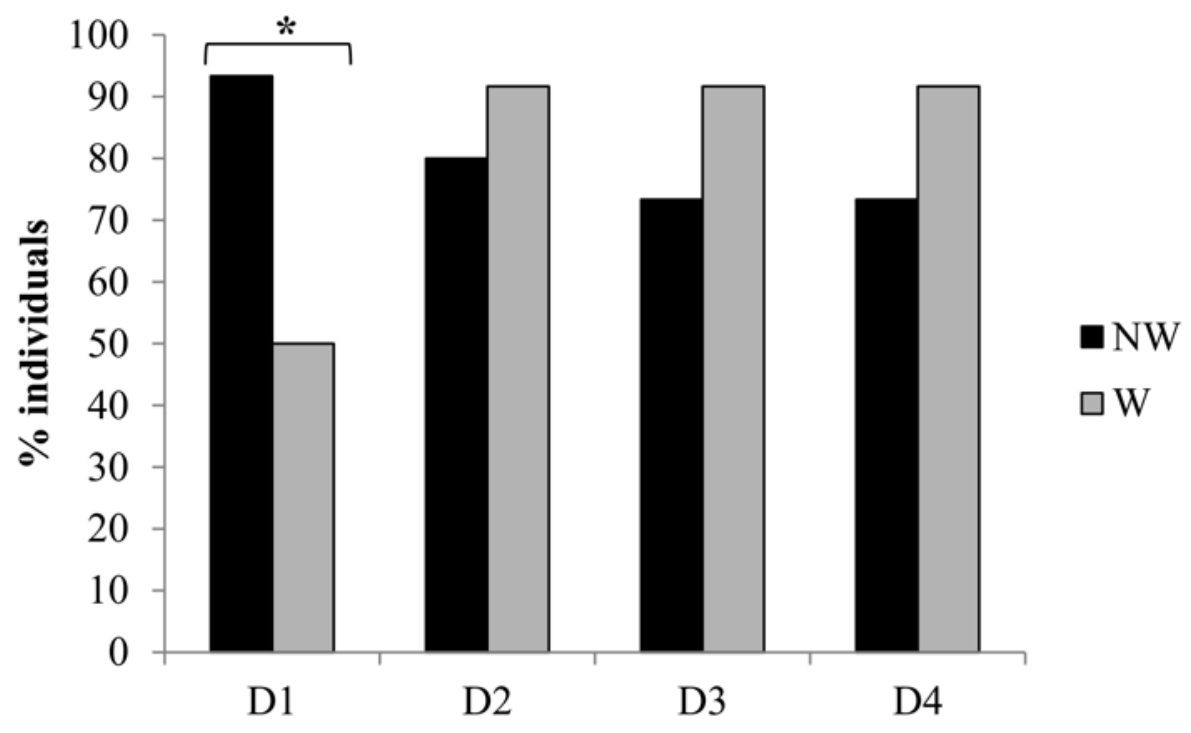

Figure 1

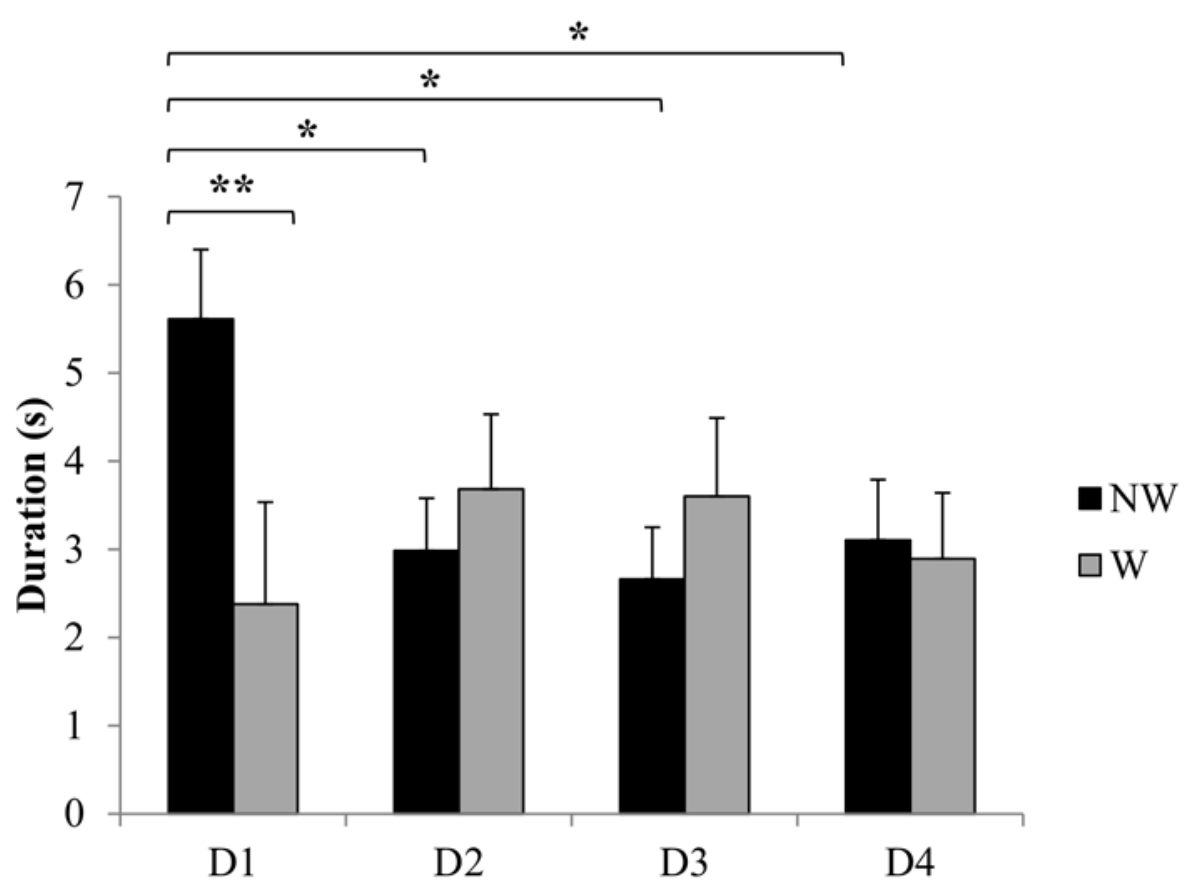

288

289

Figure 2 